DOI: $10.17805 /$ zpu.2019.3.16

\title{
Современные угрозы информационной безопасности России в сфере науки и техники
}

\author{
И. А. КРЫЛОВА \\ ИНСТИТУТ ФИЛОСОФИИ РАН
}

В статье дан анализ современных угроз информационной безопасности России в сфере науки и техники. Показано, что в условиях глобализации к внешним угрозам информационной безопасности России в данной сфере относятся: стремление Запада различными средствами, включая санкции, особенно после «Крымской весны», ограничить развитие научно-технического потенциала Российской Федерации; жесткое противодействие мировых держав созданию в нашей стране новых конкурентоспособных информационных технологий; попытка ведущих государств мира получить доступ к научно-техническим ресурсам Российской Федерации и новейшим научным результатам российских исследователей.

Обосновано, что современными внутренними угрозами информационной безопасности России в сфере науки и техники являются: сокращение финансирования НИОКР, падение престижа ученого, а также «утечка» новейших идей и разработок из России; массовая эмиграция отечественных ученых и технических специалистов в другие страны; дефицит в стране высококвалифицированных кадров в области обеспечения информационной безопасности.

Подчеркнуто, что серьезную внутреннюю угрозу представляет также продолжающееся неолиберальное реформирование науки, которое ведет к дальнейшей утечке «мозгов» и новейших научных результатов за границу.

Сделан вывод о необходимости выработки эффективных мер противодействия внешним и внутренним угрозам информационной безопасности Российской Федерации в сфере науки и техники для преодоления технологической зависимости нашей страны от ведущих западных государств и возвращения России в число научных сверхдержав.

Ключевые слова: Россия; США; Запад; санкции; информационная безопасность; российская наука; утечка мозгов; Российская академия наук; реформирование науки; технологическая зависимость; научно-технический прогресс; научная сверхдержава

\section{ВВЕАЕНИЕ}

R XXI в., когда все сферы современного общества замкнуты на науку, научно-технические инновации являются главным условием прогресса и конкурентоспособности на международной арене. Поэтому на реальное лидерство в мире могут претендовать лишь те страны, которые обладают наивысшей степенью развитости научно-тех- 
нического прогресса. В условиях глобализации и ожесточенного информационного противоборства государств за доминирование на мировой арене особое значение для развития России представляет обеспечение информационной безопасности в сфере науки и техники. $\mathrm{K}$ главным объектам обеспечения информационной безопасности в данной сфере, согласно Аоктрине информационной безопасности России, относятся, во-первых, новые результаты как фундаментальных, так и прикладных научных исследований, от которых непосредственно зависит социально-экономическое, научно-техническое развитие и «технологический прорыв» России; во-вторых, новые научные открытия, а также новейшие технологии, экспериментальные промышленные образцы и уникальное оборудование; в-третьих, национальная система подготовки научных и технических кадров (Аоктрина информационной ... , 2000: 206-207). Целью статьи является выявление и анализ основных современных внешних и внутренних угроз информационной безопасности России в сфере науки и техники.

\section{ВНЕШНИЕ УГРОЗЫ}

В настоящее время одной из основных Внешних угроз информационной безопасности России в сфере науки и техники является попытка передовых мировых держав всевозможными мерами затормозить научно-технический прогресс и ограничить развитие научно-технического потенциала России (там же: 207). По существу, с этой целью США и Западом после «Крымской весны» и начала вооруженного конфликта в Аонбассе, были введены и продолжают ужесточаться антироссийские санкции (хотя к нашей стране они в той или иной форме применялись всегда).

$\mathrm{K}$ сожалению, после развала СССР Россия находится в технологической зависимости от высокоразвитых стран, поскольку отечественные отрасли электронной промышленности до настоящего времени не способны создавать наукоемкую продукцию, которая была бы конкурентоспособна на мировом рынке. Это закономерно приводит к использованию зарубежных информационных технологий при создании национальной информационной инфраструктуры, что свидетельствует о значительном научно-техническом отставании нашей страны от развитых государств.

В условиях глобализации ведущими государствами мира, и прежде всего США, преследуется стратегическая цель значительного технологического отрыва и жесткого противодействия созданию в нашей стране конкурентоспособных информационных технологий нового поколения, что также представляет внешнюю угрозу информационной безопасности России в сфере науки и техники (там же: 196). Чтобы сохранить свое дидерство в экономической, научно-технической и военной области на международной арене, западные страны, особенно США, огромное значение придают «утечке умов» из других государств, в том числе из России. После распада Советского Союза с целью выявления и «вербовки» наиболее способных и талантливых российских ученых проводились различные международные симпозиумы, конференции, семинары, выставки, презентации и т. А. Повышенный интерес для американцев представляли прежде всего специалисты из научно-технической сферы и оборонной промышленности, высочайшая квалификация которых оказалась невостребованной в те годы в России. Случалось, что в погоне за лучшей жизнью наши соотечественники, уезжающие за границу, забирали с собой новые оригинальные идеи своих бывших коллег по работе, расчеты, чертежи и даже образцы новой продукции. Особое внимание уделялось талантливым студентам, аспирантам и молодым специалистам, которым предлагалось работать в американских и европейских научных центрах нередко даже 
за счет западной стороны, многие из которых стали «невозвращенцами». Поэтому в настоящее время попытка западных стран, особенно США, получить доступ к новейшим результатам научных исследований наших ученых является одной из внешних угроз информационной безопасности России в сфере науки и техники (там же: 207).

\section{ВНУТРЕННИЕ УГРОЗЫ}

Как известно, в XXI столетии в США, ЕС, Китае и большинстве передовых стран образование и наука являются высшим приоритетом государства. В России же в результате проводимых с начала 1990-х гг. и по сей день неолиберальных реформ научно-технический потенциал страны продолжает деградировать. «К числу основных внутренних угроз информационной безопасности России в области науки и техники следует отнести сохраняющуюся сложную экономическую ситуацию, ведущую к резкому снижению финансирования научно-технической деятельности, временному падению престижа научно-технической сферы, утечке за рубеж идей и передовых разработок» (там же; курсив наш. - И. К.). Однако в Аоктрине информационной безопасности Российской Федерации ничего не говорится о массовой эмиграции ученых и технических специалистов в другие страны, что, на наш взгляд, также представляет серьезную внутреннюю угрозу информационной безопасности России в данной сфере.

Следует отметить, что за прошедшие десятилетия существенное ухудшение материального положения ученых привело к сокращению на треть численности научных работников в России. Наиболее тяжелые потери (более $70 \%$ сотрудников) понесли институты Российской академии наук и отраслевые институты. В результате в настоящее время все институты Российской академии наук - «возрастные». Так, например, в Институте философии РАН, где осталось к настоящему времени 254 научных сотрудника (от 25 до 95 лет), 85 молодых специалистов до 39 лет, а значительную часть научного коллектива составляют 70-летние научные работники и 35 ученых старшего поколения от 80 до 95 лет. Из них - 99 докторов философских наук и 115 кандидатов философских наук. Причем в академических институтах естественная убыль ученых, к сожалению, ускоряется. Приходится констатировать также, что за эти годы около $30 \%$ научных сотрудников ушли из науки в другие структуры, в частности в различные коммерческие организации. Многие ученые выехали за рубеж, причем в самом трудоспособном возрасте - моложе 40 лет. Фактически за три десятилетия из России эмигрировала интеллектуальная элита, что значительно подорвало научный потенциал страны.

К сожалению, нет статистики, которая бы раскрывала структуру эмиграции по профессиональным и образовательным признакам. Также практически невозможно в отсутствие достоверной статистики дать точную оценку в денежном выражении утраты научно-технических позиций страны за прошедшие 30 лет.

Представляется, что в России в результате нового этапа реформирования науки, в частности академической, продолжится процесс «утечки мозгов» за рубеж.

«Государство намеревается оказывать поддержку лишь тем представителям науки, - пишет Т. В. Наумова, - кто имеет высокие показатели исследовательской активности и цитируемости в ведущих западных изданиях...» (Наумова, 2014: 37). Правительством РФ поставлена задача к 2020 г. повысить долю публикаций российских исследователей в международных научных журналах с 2 до 3\%, что представляется странным в условиях ужесточения западных санкций. Тем более что базы данных Web of Science и Scopus не объективно отражают показатели научных работ на русском языке, о чем неоднократно писали отечественные ученые. В них отсутствует 
большая часть российских журналов, особенно по социогуманитарным наукам (в том числе по философии), которые изучают проблемы современного российского общества, так как не каждый международный научный журнал (тем более американский или европейский) опубликует статьи на сугубо внутрироссийские темы. Это свидетельствует о полной неадекватности существующего ныне подхода к оценке вклада отечественной науки, прежде всего социогуманитарной, в мировую.

На наш взгляд, нынешняя директива Министерства науки и высшего образования РФ, согласно которой российские ученые должны публиковаться прежде всего в журналах, входящих в базу данных WoS и Scopus, представляет внутреннюю угрозу информационной безопасности России в сфере науки и техники (что, кажется, не осознают чиновники и «эффективные менеджеры» данного ведомства). Прежде всего это касается публикаций российских ученых в области естественных и технических наук, в которых могут содержаться новые результаты научных исследований, представляющие важность для социально-экономического, научно-технического и технологического развития нашей страны и являющиеся объектами обеспечения информационной безопасности России в сфере науки и техники. Как правило, зарубежными изданиями отслеживаются перспективные молодые ученые. Поэтому данное указание Министерства науки и высшего образования РФ ведет не к увеличению «вклада» российской науки в мировую, а, по существу, к легальной «утечке» из страны новых научных результатов отечественных ученых и подрыву информационной безопасности России в данной области.

Показательно, что после регистрации в базах данных WoS, Scopus и в ORCID отечественным ученым (проблематика исследований которых представляет интерес на Западе) сразу «посыпались» заманчивые предложения: принять участие в международных научных конференциях, стать членом редколлегии или главным редактором того или иного иностранного журнала и многие другие. В дальнейшем не исключено предложение отдельным специалистам «переехать» на постоянное место жительства в западную или даже «незападную» страну, что может спровоцировать новую волну эмиграции. Поэтому к внутренним угрозам информационной безопасности Российской Федерации в сфере науки и техники относится не только снижение эффективности системы образования, произошедшее за последние десятилетия в нашей стране, но и недостаточное количество высококвалифицированных кадров, особенно в области информационных технологий (Аоктрина информационной ..., 2000: 197).

Правительством РФ предполагается увеличить к 2020 г. долю исследователей в возрасте до 39 лет до трети от общего числа научных работников, зарплата которых должна быть вдвое выше средней по региону (сегодня в системе институтов Российской академии наук оклад младшего научного сотрудника без ученой степени составляет всего 13 тыс. рублей). Что касается докторов наук, то многим предлагают перейти на полставки при сохранении зарплаты. Таким образом, большинство институтов, подведомственных Министерству науки и высшего образования РФ, отчитываются перед министром М. Котюковым о повышении зарплат ученым (в соответствии с Указом Президента РФ), который, ссылаясь на эти данные, по существу, дезинформирует высшее политическое руководство страны. В результате, зарплата для «отчета» и реальная сумма в банковских выписках могут отличаться в два и более раза. Иначе говоря, например: в Москве в бухгалтерском отчете у доктора наук - 70 тыс. рублей, а в реальности - всего лишь 40 тыс. рублей, а к концу года около 30 тыс. рублей. Поскольку «утечка мозгов» продолжается и принимает угрожающие масштабы, это сви- 
детельствует о продолжающейся невостребованности отечественной науки в России и необходимости социальной защиты ученых, создания в стране достойных условий для молодых специалистов и снижения стимулов для әмиграции, что позволит обеспечить преемственность и смену поколений исследователей без утраты научного потенциала России. «Иначе в стране исчезнет необходимая “критическая масса умов”, - подчеркивает член-корреспондент РАН С. М. Рогов, - без которой научный прогресс невозможен» (Рогов, 2010: 587).

Этого, кажется, не понимают чиновники Министерства науки и высшего образования РФ, политика которого в настоящее время направлена на дальнейшее сокращение численности ученых (якобы для увеличения вложений в науку и улучшения условий Аля научной работы оставшимся научным кадрам), что в действительности может привести к резкому падению качественного уровня научных исследований. В частности, об этом свидетельствует происходящее ныне значительное сокращение количества университетов и закрытие кафедр философии в нашей стране. Наряду с этим предполагается сокращение числа академических институтов (якобы с целью повышения эффективности фундаментальных исследований), что на практике оборачивается простым изъятием собственности (зданий, земли и пр.), принадлежащей научным организациям. Наиболее показательный пример - история Института философии PAH, здание которого было передано для расширения Музея изобразительных искусств им. А. С. Пушкина (где реконструкция до сих пор так и не начиналась). Коллектив Института философии РАН был волюнтаристски «выдворен»на Таганку, несмотря на 90-летнюю историю и мировую известность, и подобная участь ожидает многие другие академические институты Российской академии наук.

\section{ЧИНОВНИЧИЙ ПРОИЗВОА}

Надо сказать, что последние решения и действия Министерства науки и высшего образования РФ в отношении к ученым, в частности Российской академии наук, ведут, по существу, к подрыву информационной безопасности России в сфере науки и техники и вызывают у представителей научной общественности страны чрезвычайную озабоченность.

Во-первых, в настоящее время начинается реформирование знаменитого Академического городка в Новосибирске (где построен самый большой коллайдер), в собственности которого находится 285 объектов (включающих общежитие, торговые центры, больницы, детские сады, спортивные комплексы и даже лес). В 2013 г. Федеральным агентством научных организаций (ФАНО) было полностью прекращено государственное финансирование данных объектов, содержание и ремонт которых осуществлялись на средства, полученные от аренды некоторых помещений Академического городка. Ныне вместо строительства второго Академического городка, о чем говорил Президент РФ, академикам планируется оставить всего 22 объекта (из них 17 объектов - это служебные квартиры), что фактически означает изъятие всей инфраструктуры, без которой Академгородок существовать не может. Ао настоящего времени все объекты принадлежали СО РАН. Ныне их значительная часть будет передана в пользование Министерства науки и высшего образования РФ. При этом неизвестно, на чей баланс они будут поставлены. В Правительстве РФ готовятся документы по лишению Сибирского отделения РАН права на управление имуществом и землей новосибирского Академгородка. В связи с информацией о передаче имущества Сибирского отделения РАН в федеральную собственность совет молодых ученых 
СО РАН подготовил обращение к Президенту РФ, в котором выразил озабоченность по поводу реализации проекта «Академгородок-2»1. Аумается, что следующим объектом и «жертвой» реформирования станет Институт Аальнего Востока Российской академии наук.

Во-вторых, Президенту РАН академику А. Сергееву Министерством финансов РФ было отказано в предоставлении 1 млрд рублей в год на программы по международному сотрудничеству и популяризации науки, а также на разработку стратегии научно-технологического развития России (в то время как в Роскосмосе происходили многомиллиардные хищения). Руководство министерства посчитало, что данные программы Российской академии наук не нужны. В результате был сорван визит делегации РАН в Японию2. Такое отношение к науке и ученым, по существу, свидетельствует о ненужности научных исследований в стране и фактически продолжающемся уничтожении Российской академии наук, 300-летие которой приближается.

B-третьих, в Петербурге 26 марта 2019 г. закрыт на неопределенный срок архив РАН (АРАН), владеющий бесценной коллекцией документов, собранных за 300 лет отечественной истории начиная с Петра Первого до 30-х гг. XX в., из-за прекращения финансирования. Коллектив АРАН в своих письмах на имя Президента РФ и министра науки и высшего образования РФ предупреждал, что из-за проблем с долгами и судебными исками архиву грозит закрытие, что и произошло. Похоже, что АРАН в Москве ждет такая же участь. В московском архиве за долги отключены телефонная связь и электричество. Опасность состоит в том, что длительное отключение кондиционеров может привести к повреждению оригинальных рукописей и книг, которые находятся в архиве ${ }^{3}$. А это представляет прямую угрозу информационной безопасности Российской Федерации в сфере науки и техники. Еще в декабре 2017 г. сотрудники АРАН провели круглый стол по теме «Сохраним ли мы документальное наследие науки», на котором было заявлено: «Приходится констатировать, что реформа РАН, начатая в 2013 году, без преувеличения поставила под вопрос само существование всего этого национального богатства, внесла хаос в академическое архивное дело...» $\rangle^{4}$ Поскольку АРАН утратил юридическое право на хранение документов, большинство архивов научных учреждений остаются ныне «бесхозными». Очевидно, что руководство Министерства науки и высшего образования РФ не справляется со своей основной задачей, а именно материальным обеспечением деятельности научных учреждений, в частности Российской академии наук. А если в государстве не находится денег ни на науку, ни на архивы, это значит, что у страны есть другие приоритеты.

В-четвертых, в феврале 2019 г. на официальном сайте Российского научного фонда и в СМИ появились сообщения, согласно которым Министерством финансов РФ прекращено финансирование проектов (7,3 млрд рублей) по приоритетным направлениям научно-технологического развития (что можно расценить как невыполнение указов Президента РФ)5. По словам директора Российского научного фонда (РНФ) А. Хлунова, приостановка касается государственных программ «Проведение исследований научными группами под руководством молодых ученых» (где заявлено 313 проектов) и «Проведение исследований научными лабораториями мирового уровня» якобы из-за отсутствия необходимого правительственного постановления (которое было утверждено Минфином еще 21 февраля 2019 г.). Причем на долю грантов приходится от половины до двух третей зарплаты молодых научных сотрудников.

Как известно, еще в июле 2016 г. свыше 200 крупнейших российских ученых написали «Письмо-200» о катастрофической ситуации, сложившейся в отечественной на- 
уке, обосновывая необходимость принятия срочных мер высшим политическим руководством страны (на которое, однако, не было получено официального ответа).

В 2017 г. 400 наиболее известных ученых, включая академиков РАН, подписали открытое письмо Президенту РФ, где говорилось о развале отечественной науки, о том, что новый стиль руководства наукой, принятый после реформы РАН, на самом деле науку разрушает, не оставляя научным учреждениям ни академической, ни юридической свободы, ни денег. В письме обосновывалось требование полного вывода академической науки из-под юрисдикции ФАНО: «К научным организациям пытаются приложить заведомо для них неприменимые правила обычных бюджетных учреждений, совершенно не учитывая творческий и поисковый характер работы исследователей. Научные работники должны “планировать" - сколько они сделают открытий, сколько и в каких журналах они опубликуют статей в ближайшие несколько лет. Такое планирование в принципе невозможно, и соответствующие требования ведут лишь к... обману. Это же касается и смехотворного расчета нормо-часов для выпуска научной продукции, что сводится к лихорадочной подгонке под необходимые показатели... Последние нововведения ФАНО увязывают запланированный рост финансирования институтов РАН в последующие годы с абсурдным требованием пропорционального роста числа публикаций... Весь стиль и методы работы ФАНО объективно направлены на разрушение науки как таковой, не говоря уже о творческой атмосфере, необходимой для научной деятельности» 6 .

В результате ФАНО было ликвидировано и создано Министерство науки и высшего образования РФ. Его вновь возглавил М. Котюков, который продолжает политику «реформирования» несмотря на то, что прошедшие 6 лет наглядно показали колоссальный урон, нанесенный отечественной фундаментальной науке, невосполнимый ущерб научного потенциала страны. Основной целью некомпетентных в науке чиновников является полное вытеснение РАН из триллионных национальных проектов и замена ученых «эффективными менеджерами». В открытом письме российских ученых к Президенту РФ были приведены пророческие слова Г. Галилея: «...назначать лиц, совершенно невежественных в науке... судьями над людьми учеными, наделяя их властью поступать с последними по своему усмотрению, - это такие нововведения, которые способны разрушить государство ${ }^{7}$.

В связи с этим закономерно возникает вопрос, о каком «технологическом прорыве» России может идти речь при таком отношении к ученым некомпетентных чиновников, которое фактически ведет не только к подрыву информационной безопасности страны в сфере науки и техники, но и национальной безопасности государства?

\section{ЗАКАЮЧЕНИЕ}

Аля того чтобы Россия в новом столетии смогла занять достойное место среди развитых стран и вновь стать мировой «научной сверхдержавой», требуется продуманная государственная научно-техническая политика, а не бесконечное неолиберальное реформирование российской науки, в частности Российской академии наук.

Аля осуществления технологического прорыва необходим переход России на инновационный путь, что предполагает приоритетное финансирование сферы образования и науки (как во всех развитых странах). Однако наши финансовые власти в силу господства неолиберальных догм продолжают сокращать государственные расходы на образование и науку, которые остаются недофинансированными. Между тем в XXI столетии новые «прорывные» технологические знания, на основе которых за- 
тем создаются инновационные технологии и продукты, формируют НИОКР. «Можно утверждать, что система НИОКР, - пишут А. А. Акаев и А. В. Коротаев, 一 это, по существу, современная отрасль экономики, производящая инновационные технологии и продукты и являющаяся основным двигателем технологического прогресса, который способен увеличивать как производительность труда, так и производительность капитала и других факторов роста экономики» (Акаев, Коротаев, 2019: 11).

Приходится констатировать, что у нас государственные инвестиции в НИОКР составляют всего около 0,8\% ВВП (как в США и Японии). Частный сектор в США инвестирует в НИОКР около 1,6\% ВВП, в Японии - 2,6\% ВВП, в России же такие инвестиции составляют только 0,3\% ВВП (т. е. в 5-9 раз меньше, чем в указанных странах) (там же). Несмотря на то что государственные инвестиции являются важнейшим фактором в создании инновационных разработок, например, в странах ОЭСР доля расходов на НИОКР в 1,5-2 раза ниже доли частных инвестиций, которые осуществляют крупнейшие промышленные компании. В Российской Федерации, напротив, уровень финансирования НИОКР бизнесом очень незначителен, что обрекает страну на существенную технологическую зависимость от развитых в технологическом отношении западных стран.

К сожалению, в России, несмотря на декларации о необходимости технологического прорыва, спроса на инновации нет, а в экономике до сих пор наблюдается слабая инновационная активность и чрезвычайно низкий спрос на НИОКР в области высоких технологий. Зато российские инновации пользуются большим спросом за границей, Аля чего в России (на наш взгляд) был создан инновационный центр «Сколково». Надо сказать, что данный проект сразу вызвал вопрос у представителей российской научно-технической интеллигенции: для каких целей нужен новый инновационный центр - структура, параллельная Российской академии наук и существующим наукоградам, в котором будут работать зарубежные ученые, в то время как российские специалисты остаются невостребованными в стране? Поскольку финансирование «Сколково» сравнимо с бюджетом Российской академии наук, можно сделать вывод, что оно осуществляется фактически за счет недофинансирования многих отечественных научно-исследовательских институтов. Поэтому отношение российского научного сообщества к данному проекту до сих пор весьма противоречиво. Аишь отдельные ученые позитивно оценивают его создание как «площадку» для международного сотрудничества в сфере науки и техники. Многие отечественные исследователи считают, что рациональнее было бы использовать имеющийся потенциал наших наукоградов и институтов РАН. Значительная часть российской научной общественности критически оценивает создание данного иннограда, считая его очагом коррупции и воровства, о чем неоднократно сообщают отечественные средства массовой информации. На наш взгляд, поскольку инновационный центр «Сколково» фактически «работает» на экономику других стран и российские инновации легально «уходят» за рубеж, его деятельность ведет к подрыву информационной безопасности России в сфере науки и техники.

Согласно прогнозам, к 2020 г. расходы на НИОКР в Российской Федерации должны увеличиться до $3 \%$ ВВП. При этом предполагается, что в самой структуре затрат произойдут качественные изменения, а именно нагрузка на федеральный бюджет сократится. К 2050 г. финансирование НИОКР в России должно достичь 4-5\% ВВП (как в большинстве высокотехнологичных стран), чтобы не оказаться на «задворках» цивилизации.

Хотелось бы надеяться, что реализация на практике государственной программы по развитию науки и технологий до 2020 г. позволит России сохранить фундаментальную науку и РАН от окончательного разгрома (Крылова, 2015: 699-721), совершить техно- 
логический «прорыв», вернуть себе статус научной сверхдержавы и занять достойное место среди развитых экономик мира. Однако очевидно, что это возможно лишь при условии выработки эффективных мер противодействия современным внешним и внутренним угрозам информационной безопасности России в сфере науки и техники.

\section{ПРИМЕЧАНИЯ}

1 Власти планируют забрать у РАН большую часть Академгородка в Новосибирске (2019)// Новости сибирской науки. 5 марта. URL: http://www.sib-science.info/ru/sbras/ran-bolshuyu05032019 (дата обращения: 05.03.3019).

2 РАН: Минфин отказался выделить 1 млрд рублей на программы по международному сотрудничеству и популяризации науки (2019) [Электронный ресурс] // Новая газета. 20 марта. URL: https://www.novayagazeta.ru/news/2019/03/20/150156-ran-minfin-otkazalsya-vydelit-1mlrd-rubley-na-programmy-po-mezhdunarodnomu-sotrudnichestvu-i-populyarizatsiinauki?utm_source=yxnews\&utm_medium=desktop (дата обращения: 20.03.2019).

3 Ваганов А. (2019) Архив Академии наук все-таки закрывают [Электронный ресурс] // Независимая газета. 4 апреля. URL: http://www.ng.ru/science/2019-04-04/100_arhiv040419.html (дата обращения: 04.04.2019).

${ }^{4}$ Вольтская Т. (2019) «Зачем много знать?» Почему закрылся архив Академии наук [Электронный ресурс] // Радио Свобода. 19 апреля. URL: https://www.svoboda.org/a/29891938.html (дата обращения: 19.04.2019).

5 Михальченко Е., Викулова А., Черных А. (2019) Над учеными поставили эксперимент. РНФ объявил о приостановке финансирования сотен научных проектов [Электронный ресурс] // Коммерсант. 28 февраля. https://www.kommersant.ru/doc/3896438 (дата обращения: 15.04.2019).

6 Открытое письмо Президенту Российской Федерации В. В. Путину (2017) [Электронный ресурс]// Коммерсант. 27 декабря. URL: https://www. Kommersant.ru/doc/3509262 (дата обращения: 15.04.2019).

7 Там же.

\section{СПИСОК АИТЕРАТУРЫ}

Акаев, А. А., Коротаев, А. В. (2019) Начало фазы подъема шестой кондратьевской волны // Век глобализации. № 1. С. 3-17.

Глазьев, С. (2016) Экономика будущего. Есть ли у России шанс? М. : Книжный мир. 640 с.

Аоктрина информационной безопасности Российской Федерации (2000) // Безопасность. № 1-12. С. 196-197.

Крылова, И. А. (2016) Реформа РАН: к истории вопроса (Реформирование РАН или разгром отечественной фундаментальной науки?) // Императорская академия наук и художеств, Академия наук СССР, Российская академия наук - триединая академия. К 290-летию основания РАН / сост. и отв. ред. А. В. Ажохадзе. СПб. : Мир. 880 с. С. 699-721.

Рогов, С. М. (2010) Россия должна стать научной свехдержавой // Вестник РАН. №7. C. 579-590. $176 \mathrm{c.}$

Наумова, Т. В. (2014) Эмиграция ученых из России. М. : Канон+ ; РООИ «Реабилитация».

Аата поступления: 27.05.2019 2.

\section{CONTEMPORARY THREATS TO INFORMATION SECURITY OF RUSSIA \\ IN THE FIELD OF SCIENCE AND TECHNOLOGY \\ I. A. KRYLOVA \\ RAS INSTITUTE OF PHILOSOPHY}

The article analyzes the current threats to the information security of Russia in the field of science and technology. It is shown that in today's global world there exist the following external threats to 
the information security of Russia in the field of science and technology: the desire of the Western world to limit the development of the scientific and technical potential of the Russian Federation by various means, including sanctions, especially after the "Crimean Spring"; the tough opposition of world powers to the creation of new competitive information technologies in our country; the attempt of the leading states of the world at unauthorized access to the scientific and technical resources of the Russian Federation and the latest scientific results achieved by Russian scientists.

The article substantiates that modern internal threats to the information security of Russia in the field of science and technology include a reduction in the financing of research and development activities, a sharp drop in the prestige of a scientist, the "leakage" of domestic advanced ideas and developments abroad, massive emigration of domestic scientists and technical specialists to other countries, a lack of highly qualified personnel in the field of information security in the country.

It is emphasized that the potential internal threat to the information security of the Russian Federation in the field of science and technology is also represented by the ongoing neoliberal reform of science, which leads to further brain drain and the latest scientific results from Russia.

The author draws a conclusion about the need to develop effective measures to counter external and internal threats to the information security of the Russian Federation in the field of science and technology to overcome the technological dependence of our country on the leading Western states and to make Russia a major scientific superpower again.

Keywords: Russia; USA; West; sanctions; information security; Russian science; brain drain; Russian Academy of Sciences; reforms of science; technological dependence; scientific and technical progress; scientific superpower

\section{REFERENCES}

Akaev, A. A. and Korotaev, A. V. (2019) Nachalo fazy pod»ema shestoi kondrat'evskoi volny. Vek globalizatsii, no. 1, pp. 3-17. (In Russ.).

Glaz'ev, S. (2016) Ekonomika budushchego. Est' li u Rossii shans? Moscow, Knizhnyi mir. 640 p. (In Russ.).

Doktrina informatsionnoi bezopasnosti Rossiiskoi Federatsii (2000). Bezopasnost', no. 1-12, pp. 196-197. (In Russ.).

Krylova, I. A. (2016) Reforma RAN: k istorii voprosa (Reformirovanie RAN ili razgrom Otechestvennoi fundamental'noi nauki?). In: Imperatorskaia akademiia nauk $i$ kbudozbestv, Akademiia nauk SSSR, Rossiiskaia akademiia nauk - triedinaia akademiia. K 290-letiiu osnovaniia RAN / comp., ed. by. D. V. Dzhokhadze. St. Petersburg, Mir. 880 p. Pp. 699-721. (In Russ.).

Rogov, S. M. (2010) Rossiia dolzhna stat' nauchnoi svekhderzhavoi. Vestnik RAN, no. 7, pp. 579-590. (In Russ.).

Naumova, T. V. (2014) Emigratsiia uchenykb iz Rossii. Moscow, Kanon+; ROOI «Reabilitatsiia». 176 p. (In Russ.).

Submission date: 27.05.2019.

Крылова Ирина Анатольевна - доктор философских наук, ведущий научный сотрудник сектора философских проблем политики Института философии Российской академии наук. Aдрес: 109240, Россия, г. Москва, ул. Гончарная, д. 12, стр. 1. Тел.: +7 (495) 697-91-89. Эл. адрес: tatyanawings@gmail.com

Krylova Irina Anatolyevna, Doctor of Philosophy, Leading Research Fellow, Sector of the Philosophical Issues of Politics, Institute of Philosophy, Russian Academy of Sciences. Postal address: 12, Bldg. 1, Goncharnaya St., Moscow, Russian Federation, 109240. Tel.: +7 (495) 697-91-89. E-mail: tatyanawings@gmail.com 